\title{
Investigating the Effect of Empowerment on Employees’ Occupational Self-Efficacy
}

\author{
Neda NAFARI ${ }^{1, *}$, Sajad VATANKHAH ${ }^{2}$ \\ ${ }^{1}$ Department of Governmental Management, North Tehran Branch , Islamic Azad University, \\ Tehran, Iran. \\ 2 Department of Governmental Management, North Tehran Branch, Islamic Azad University, \\ Tehran, Iran.
}

\begin{abstract}
The present descriptive-survey research aims to study the impact of empowerment on occupational self-efficacy of the employees in the Greater Tehran branches of Mehr Eghtesad Bank. The statistical population is comprised of all 600 employees of Mehr Eghtesad Bank working in branches of the Greater Tehran. Using Morgan table, the sample size is determined to be 234. Sampling is carried out using simple random method. In order to assess the studied variables, employee empowerment questionnaire and work self-efficacy scale have been used. The validity of the questionnaires is confirmed by experts. Using Cronbach's Alpha, the reliability of empowerment questionnaire is measured to be 0.84 , and the reliability of occupational self-efficacy is assessed to be 0.81 . In order to analyze the data, descriptive statistics as well as inferential statistics (univariate regression and stepwise regression) have been used. Research results indicate that empowerment and all its dimensions (meaningfulness, competence, autonomy, and impact) have a positive and significant effect on self-efficacy of employees in Greater Tehran branches of Mehr Eghtesad Bank. The results also suggest that the three dimensions of autonomy, impact, and meaningfulness can predict the self-efficacy of employees in Greater Tehran branches of Mehr Eghtesad Bank.
\end{abstract}

Keywords: empowerment, occupational self-efficacy, human resources, Mehr Eghtesad Bank

\section{1- Introduction}

After years of experience, the world has come to the conclusion that is an organization wants to become a pioneer in its business and tries not to fall behind in the competition it should make best use of expert, creative, and motivated human resources [1].

Empowerment offers potentials to make use of human capabilities which are not being fully utilized. In this sense, human resource empowerment means creating a set of required capacities

* Corresponding author:

Email: n nafari@iau-tnb.ac.ir 
in the employees in order to enable them create added value in the organization and carry out their organizational task with efficiency and effectiveness. In other words, empowerment means giving power. In this sense, we help individuals to enhance their self-esteem and overcome their inadequacies. In fact, the purpose of empowerment is to provide the best intellectual resources related to each field of performance [2].

On the other hand, self-efficacy is a major topic in today's psychology which has attracted the attention of many psychologists and researchers. These scholars search for numerous theories on solutions to improve or cultivate self-efficacy. Based on theories and conducted studies in the past decades, numerous therapeutic approaches are focused on self-efficacy and its improvement. Behavioral-cognitive therapy and reality therapy are among such methods. Individuals who feel good about themselves can easily overcome the conflicts, resist negative pressures, and enjoy life. Self-efficacy is one of the determining factors in formation of behavioral and emotional patterns; it indicates an individual's view of himself and the outside world. Feeling of being valued affects all aspects of a person's life and his view on his capabilities. Studies suggest that there is a relationship between high self-efficacy and positive personality traits. On that basis, individuals with high self-efficacy possess characteristics such as mental maturity, stability, realistic view, peace, and ability to cope with failure; on the other hand, individuals with low self-efficacy lack such characteristics. Moreover, the feeling of being valued has an enormous impact on a person's knowledge of his capabilities [3].

\section{2- Statement of Problem}

Self-efficacy is a widely used concept in studies of the Humanities. It was first introduced by Badura (1997). He defines self-efficacy as a person's belief in his capabilities to achieve a certain goal. Ever since it was introduced by Bandura, various studies in self-efficacy and its related factors have been conducted [4].

In fact, today the organizations are run in a highly competitive environment transformed constantly by marvelous developments. In a situation like this, managers do not have much time to control their employees; they must spend most of their time trying to understand the environment outside and inside the organization and leave the daily tasks to the employees. Employees can accomplish their tasks only when they know organizational goals and are equipped with required knowledge, capability, and motivation. Empowerment is an instrument which can prove useful for managers [5].

As a part of the economic system which plays an important role in the country's development, banking system has been faced with a lot of challenges in past few years. The most important of such challenges are the intense competition between banks and financial institutions, increased customer knowledge, and change in customer expectations and needs. Therefore, by accurate identification of factors contributing to customer satisfaction, banks should implement systems to attract customer and create loyalty within them [6]. 
Considering its vision on market development through development of new customer service and marketing methods as well as application of new banking services, and in order to improve its status as a pioneer organization, Mehr Eghtesad Bank should provide the necessary requirements for self-efficacy of its employees.

Considering the discussions provided here, the research faces the following question:

Does empowerment affect occupational self-efficacy of employees in Greater Tehran branches of Mehr Eghtesad Bank?

\section{3- Research necessity and importance:}

During recent years, our country's banking system has had massive transformations. The competition between banks becomes more intense everyday. Private and public banks as well as financial institutions try to gain larger shares of the market. Therefore, they seek to devise better methods to provide more diverse services and attract more customers and increase their profitability. Yet, most of them are unaware of an element which can become their competitive advantage. Human resources and organizational performance improvement are the missing links in achievement of banks' goals. In fact, motivated and unified employees are the key to a bank's prosperity or its demise. Therefore, proper attention to employees in order to cultivate capable, eager, dynamic, and creative workforce can lead any bank to success [7].

A person's self-image is one of the fundamental and important subjects of psychology which can set the background for social and educational achievement, while being affected by it as well. There is also an interaction between attitude and learning. Most theories on achievement motivation consider individuals' beliefs to be the most important factor contributing to their progress. In fact, all of these theories presume that individuals' expectations and perceptions of their own abilities play an important part in their motivation and behavior. Also, perception of incompetence in a situation creates more pressure than the quality of that situation. Individuals with low self-efficacy have pessimistic views on their own abilities and stay away from any situation that they consider to be beyond their capability. On the other hand, individuals with high self-efficacy consider hard tasks as challenges which they can overcome [8].

Requirements and conditions for improvement of self-efficacy should be provided. To this end, psychological empowerment is a beneficial factor. On that basis, cultivation of employees with self-management abilities has introduced human resource empowerment as a new paradigm which attracts many experts of management [9]. The present research helps stakeholders and authorities to take empowerment and constant control of its indices in Mehr Eghtesad Bank in Greater Tehran into consideration and use those factors to improve the organizational performance. 
Therefore, considering the importance and necessity of employee empowerment and regarding the impact of self-efficacy, the present research studies the impact of empowerment on occupational self-efficacy of employees in Greater Tehran branches of Mehr Eghtesad Bank.

\section{4- Research Literature}

\section{4-1- Employee Empowerment}

Pastor considers empowerment to be a personal phenomenon by which individuals take responsibility to do their job. This definition emphasizes on the importance of individuals for successful implementation of empowerment. According to Spitzer, psychological empowerment is a set of psychological states which refer to the way employees perceive and experience their jobs, and to the extent they believe in their role in the organization; it gives the employees selfesteem and make them eager for success [10]. Empowerment means the employees perfectly understand their duties before even being told what to do [11].

In another definition, Kanter [12] states that empowerment refers to a person's ability to decide independently and use available resources to achieve necessary objectives [10].

Smith defines empowerment as motivating individuals for further participation in making decisions which affect their activities. Through that, we can provide individuals with opportunities where they can demonstrate that they can offer and execute good ideas [13].

Conger \& Kanungo [14] define empowerment as a relational and motivational structure; in the relational sense, empowerment occurs when the power is transferred from top to bottom. As a result, employees feel ownership and control over their job. As in motivational sense, empowerment refers to employees' perception of their autonomy and control. If these individuals are empowered, they gain high energy and control over their job. In this sense, autonomy, selfevaluation, and belief in self-efficacy are strengthened.

Empowerment is the approach toward constant improvement of organizational performance realized through establishment of individuals' influence based on their competence and job descriptions; this subsequently affects the employees' performance and organization's total performance [15].

\section{4-2- Self-efficacy}

Dealing with a set of mental skills is among important issues which have attracted the attention of many psychologists in recent years. Self-efficacy is one of such issues. It originates from individual's performance and affects the capabilities of employees. Low self-efficacy or lack there of mark their failure [16].

The concept of self-efficacy is derived from the social-cognitive theory of the famous psychologist Albert Bandura, which refers to a person's belief or judgment about his/her ability 
to carry out the tasks and responsibilities. According to him, a person's prior knowledge or skills are not good predictors of his future performance; on the contrary, a person's belief in his abilities affects his performance. There is an obvious difference between having different skills and the ability to combine them with suitable methods to carry out tasks in various situations. People usually know what they should do and which skills they need to do their job, but they are usually unsuccessful in execution of those skills [17]. Self-efficacy is the feeling of competence, adequacy, and capability to adapt to life. Providing the criteria for performance increase that feeling and failing to do so would reduce it. In fact, self-efficacy refers to a person's ability to face problems in order to reach certain objectives; rather than being affected by intelligence, success depends more on characteristics such as belief in oneself, resilience, perseverance, and self-control. Bandura considers self-efficacy to be a person's belief in doing the desirable task alongside coping with the situation [18].

\section{5- Research Background}

In a study titled "the relationship between psychological empowerment, self-efficacy, and job satisfaction in employees of Western Carpet Company", Abdi [19] concludes that there is a positive and significant relationship between psychological empowerment and job satisfaction. Also, job satisfaction has a significant relationship with three dimensions of empowerment i.e. autonomy, competence, and meaningfulness. No significant relationship between job satisfaction and dimension of influence and impact has been observed. Moreover, no significant relationship between self-efficacy and empowerment has been observed. However, the impact of selfefficacy on improvement of job satisfaction is significant.

In a study titled "the impact of psychological and organizational empowerment on human resource performance (case study: Besat hospital)", Heidari [20] concludes that impact, competence, meaningfulness, autonomy, and empowerment have a positive and significant impact on job satisfaction. Also, the results of hypotheses examination point to the positive and significant impact of the variables of impact, competence, meaningfulness, and empowerment on job satisfaction. Meanwhile, autonomy has no significant impact on job commitment. Moreover, the research concludes that job satisfaction, organizational commitment, psychological empowerment, and organizational empowerment have positive and significant effects on human resource performance.

In his research, Fathi [21] studies "the effect of psychological empowerment on job performance and personal responsiveness of Urmia University in 2011-12 school years”. He concludes that the impact of psychological empowerment on job performance and personal responsiveness is positive and significant. The result of regression analysis confirms the linear relationship for prediction of job performance and personal responsiveness by the components of psychological empowerment. 
Hosseini [22] studies "the relationship between empowerment and self-efficacy and job satisfaction in secondary school managers in Shiraz". He concludes that there is a direct relationship between empowerment and self-efficacy and job satisfaction. This indicates that managers’ empowerment affects their self-efficacy and vice versa.

In a study titled "investigating the relationship between empowerment and job performance”, Barzegar \& Mohammadi [23] conclude that there is a significant relationship between components of empowerment and job performance. Also, predictor variables (components of empowerment) can predict the criterion variable (job performance).

In a study, Luthans et al. [24] conclude that self-efficacy can moderate job satisfaction. It can be a motive for improvement of organizational commitment as it reduces the tendency to quit the job.

Chan [25] argues than students with higher emotional intelligence have higher self image and self-efficacy. Their study indicates that people with stronger self-efficacy try harder to do their assignment and spend more time in order to receive better grades.

In his study titled "the relationship between self-efficacy and tendency to abandon organization in downsizing of an insurance company” Earnest [26] studies 177 employees and concludes that there is a significant relationship between job abandonment and self-efficacy.

The study by Vacharakiat [10] on the relationship between job satisfaction and organizational commitment in nurse in Philippine and US suggests that there is a significant relationship between psychological empowerment, structural empowerment, job satisfaction, and normative and affective commitment. In other words, higher empowerment of nurses in Philippine and the US increases job satisfaction and normative and affective commitment.

Chang \& Solomon [27] study the relationship between formal perceptions, situational anxiety, self-efficacy, and educational performance. The results suggest that self-efficacy has a positive and significant relationship with educational performance.

\section{6- Research concept model:}

The present research uses Spritzer et al. [28] model to assess empowerment. Based on this model, empowerment is comprised of four dimensions i.e. meaningfulness, competence, autonomy (right to choose), and impact (consequential influence). Also, Pourjafardoost [29] model is used for assessment of employees' self-efficacy. This model is comprised of four dimensions i.e. self-management, self-regulation, self-assessment, self-confidence, and selfmotivation. Figure 1 demonstrates the relationship between research variables. 


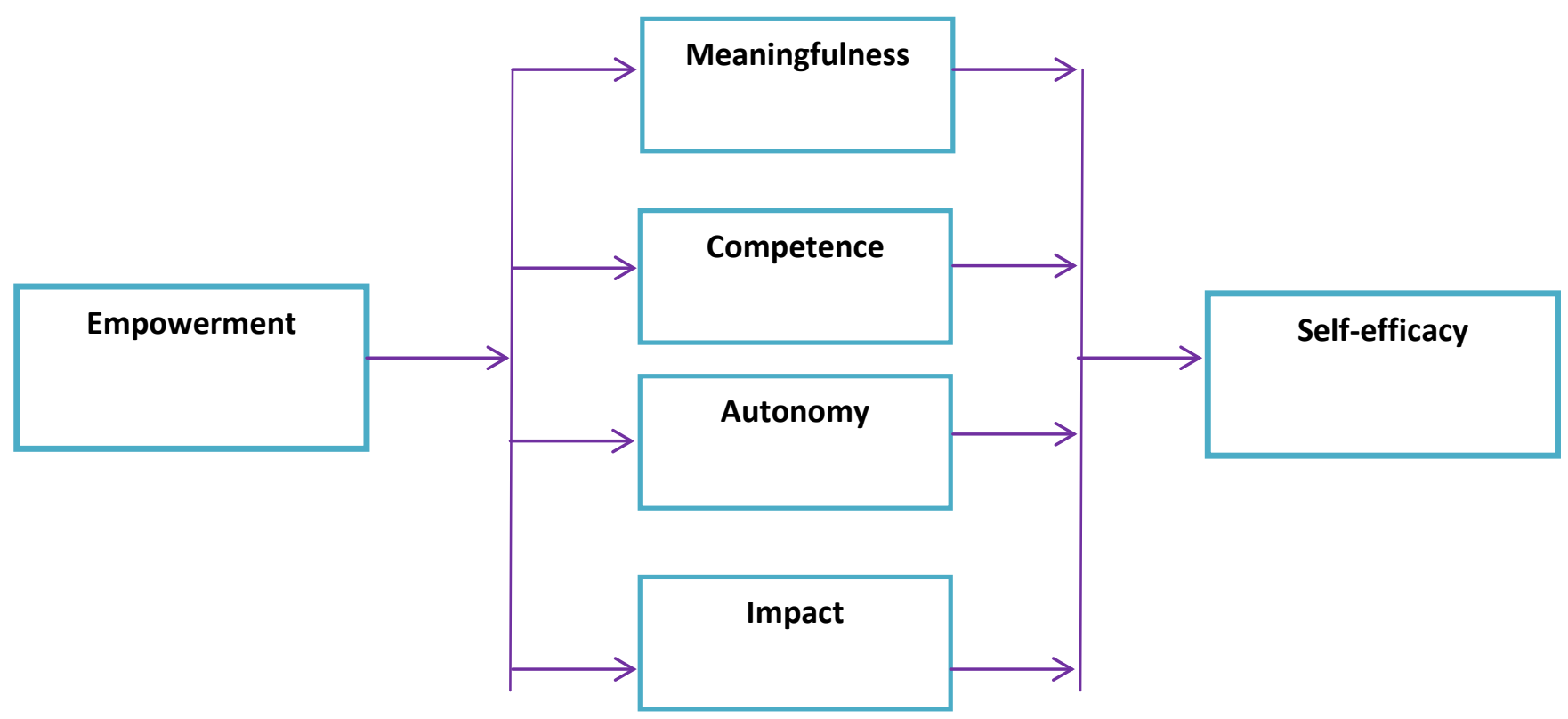

Figure 1: Research Concept Model

Therefore, based on the research concept model, the main hypothesis and subsidiary hypotheses are developed as below:

Main hypothesis: empowerment affects the self-efficacy of employees in Greater Tehran branches of Mehr Eghtesad Bank.

\section{Sub-hypotheses:}

1. Meaningfulness affects the self-efficacy of employees in Greater Tehran branches of Mehr Eghtesad Bank.

2. Competence affects the self-efficacy of employees in Greater Tehran branches of Mehr Eghtesad Bank.

3. Autonomy (right to choose) affects the self-efficacy of employees in Greater Tehran branches of Mehr Eghtesad Bank.

4. Impact (consequential influence) affects the self-efficacy of employees in Greater Tehran branches of Mehr Eghtesad Bank.

5. Dimensions of empowerment can predict occupational self-efficacy of employees in Greater Tehran branches of Mehr Eghtesad Bank. 


\section{7- Research methods:}

\section{7-1- Type and method of research}

By purpose, this is an applied study, and in terms of method and type, it is a descriptive-survey research.

\section{7-2- Statistical population}

The statistical population of the present research is comprised of all employees of Greater Tehran branches of Mehr Eghtesad Bank. According to the latest records, there are 600 individuals in this population.

\section{7-3- Sample group and sampling method}

Considering the large size of the studied population, simple random sampling method has been used. Using Morgan table, the sample size is determined to be 234.

\section{7-4- Measures of data collection}

Questionnaire is the most common instrument of data collection in survey studies. Therefore, the present research employs a researcher-realized questionnaire to collect the required information. In order to assess psychological empowerment, Spritzer (1995) questionnaire has been used. This questionnaire has four subscales i.e. meaningfulness, autonomy, impact, and competence. The components are scored based on Likert-type Five-point scale (from completely disagree to completely agree). Using Cronbach's Alpha, Vacharakiat (2008) has measured the reliability of this questionnaire to be 0.82 for autonomy, 0.88 for impact (influence), 0.79 to 0.81 for competence, 0.73 to 0.85 for meaningfulness, and 0.90 for the whole questionnaire.

\section{7-5- Questionnaire validity and reliability}

In order to determine the validity of the questionnaire, the present research uses content validity. As for face validity and content validity of the questionnaire, experts, professors, and consultants are referred to. In order to assess the reliability of the research measure, Cronbach's Alpha has been used. To this end, a primary sample is pretested using 30 questionnaires. Then, using the obtained data and with the help of SPSS software, the reliability of each subscale of the questionnaire is assessed. Based on Cronbach's Alpha, the reliability of psychological empowerment is 0.84 , and reliability of self-efficacy equals 0.81 .

\section{7-6- Method of data analysis}

The present research uses descriptive and inferential statistics to analyze the data. To this end, after the extraction of data from the questionnaire, first descriptive statistics are used to study the 
demographical features of the subjects. Then, in order to answer the research questions, inferential statistics are used. Indices such as frequency, percentage, mean, and standard deviation are used in descriptive statistics section; as for inferential statistics, KolmogorovSmirnov test is used to examine the normality of the data. Then, considering the normality of the sample data, suitable univariate regression and stepwise regression analysis are used.

\section{8- Findings}

\section{8-1- Normality test of research variables}

Before dealing with the research questions, in order to examine the normality of frequency distribution of research variables, Kolmogorov-Smirnov test is used. The results of KolmogorovSmirnov test indicate that the variable of empowerment with the value of 0.928 and significance level of 0.216 , and the variable of self-efficacy with the value of 0.835 and significance level of 0.415 have normal distribution. Assuming that the variables are at interval scale, parametric tests can be used for analysis.

\section{8-2- Univariate and Stepwise regression analysis}

Table 1: results of univariate regression analysis

\begin{tabular}{|c|l|r|r|r|r|}
\hline Independent variable & Dependent variable & $\mathrm{B}$ & Beta & $\mathrm{T}$ & $\mathrm{P}$ \\
\hline Empowerment & Occupational self-efficacy & 0.601 & 0.673 & 13.86 & 0.000 \\
\hline Meaningfulness & Occupational self-efficacy & 0.229 & 0.407 & 6.79 & 0.000 \\
\hline Competence & Occupational self-efficacy & 0.294 & 0.449 & 7.66 & 0.000 \\
\hline Autonomy & Occupational self-efficacy & 0.406 & 0.604 & 11.53 & 0.000 \\
\hline Impact (influence) & Occupational self-efficacy & 0.308 & 0.500 & 8.78 & 0.000 \\
\hline
\end{tabular}

Table 2: results of stepwise regression analysis

\begin{tabular}{|c|c|c|c|c|c|c|c|}
\hline Steps & Predictor variable & $\mathrm{R}$ & $\mathrm{R}^{2}$ & $\mathrm{~B}$ & Beta & $\mathrm{T}$ & $\mathrm{P}$ \\
\hline $1^{\text {st }}$ & Autonomy & 0.604 & 0.364 & 0.460 & 0.604 & 11.53 & 0.000 \\
\hline \multirow{2}{*}{$2^{\text {nd }}$} & Autonomy & \multirow{2}{*}{0.682} & \multirow{2}{*}{0.466} & 0.375 & 0.492 & 9.66 & 0.000 \\
& Impact & & & 0.208 & 0.337 & 6.60 & 0.000 \\
\hline \multirow{3}{*}{$3^{\text {rd }}$} & Autonomy & \multirow{3}{*}{0.713} & \multirow{2}{*}{0.508} & 0.334 & 0.439 & 8.69 & 0.000 \\
& Impact & & & 0.122 & 0.310 & 6.27 & 0.000 \\
& Meaningfulness & & & 0.217 & 4.46 & 0.000 \\
\hline
\end{tabular}

In order to determine which components of empowerment can predict self-efficacy of the employees in Greater Tehran branches of Mehr Eghtesad Bank stepwise regression analysis has been used. The obtained results from table 2 indicate that of the components of empowerment, only three (autonomy, impact, and meaningfulness) possess the criteria for entering the final regression equation for explanation of self-efficacy of the employees in Greater Tehran branches 
of Mehr Eghtesad Bank. Since the component of competence lacks the criteria, it is excluded from the equation. Also, as demonstrated in table 2, all three components of autonomy, impact, and meaningfulness are able to explain 0.50 percent of self-efficacy of the employees in Greater Tehran branches of Mehr Eghtesad Bank.

\section{9- Conclusion and discussion}

The results of the main hypothesis examination indicate that empowerment has a positive and significant impact $(\beta=0.673)$ on self-efficacy of the employees in Greater Tehran branches of Mehr Eghtesad Bank. This effect is significant at the 0.01 level. Considering the positive sign of regression coefficient, it can be said that increase in empowerment will improve occupational self-efficacy in the bank.

In this regard, the findings of the present research correspond to those of the study by Abdi et al. (2013) who conclude that there is a significant relationship between self-efficacy and empowerment. These results also correspond to the findings of Hosseini (2010) who concludes that managers' empowerment affects their self-efficacy.

Employees with higher empowerment often act beyond the official job requirements. Such employees carry out organizational tasks better and more successfully and work toward improvement of organizational activities. In fact, it can be claimed that empowerment is one of the factors contributing to improvement of self-efficacy in the organization. Managers and employees can offer better services when they are properly empowered.

The results of the first hypothesis examination indicate that meaningfulness has a positive and significant impact $(\beta=0.407)$ on self-efficacy of the employees in Greater Tehran branches of Mehr Eghtesad Bank. This effect is significant at the 0.01 level. Considering the positive sign of regression coefficient, it can be said that increase in meaningfulness will improve occupational self-efficacy in the bank.

In this regard, it can be claimed that employees with more sense of meaningfulness perceive the importance of their jobs both to themselves and to the organization, hence paying more attention to their tasks. As a result, the probably work better and take pride in their success. Such employees would naturally have higher self-efficacy.

The results of the second hypothesis examination indicate that competence has a positive and significant impact ( $\beta=0.449$ ) on self-efficacy of the employees in Greater Tehran branches of Mehr Eghtesad Bank. This effect is significant at the 0.01 level. Considering the positive sign of regression coefficient, it can be said that increase in competence will improve occupational selfefficacy in the bank. In order to improve self-efficacy, the organization should possess empowered employees who believe they have the capability to do and succeed in any task they are assigned to. 
The results of the third hypothesis examination indicate that autonomy has a positive and significant impact $(\beta=0.604)$ on self-efficacy of the employees in Greater Tehran branches of Mehr Eghtesad Bank. This effect is significant at the 0.01 level. Considering the positive sign of regression coefficient, it can be said that increase in autonomy will improve occupational selfefficacy in the bank. The results of the present research indicate that employees will demonstrate better performance when their jobs are not imposed on them, but rather accepted by them voluntarily. In this case, the employees would try to carry out their task more accurately and successfully. The reason for higher self-efficacy is the feeling within employees who believe that they have been given a choice in their work.

The results of the fourth hypothesis examination indicate that impact (consequential influence) has a positive and significant effect $(\beta=0.500)$ on self-efficacy of the employees in Greater Tehran branches of Mehr Eghtesad Bank. This effect is significant at the 0.01 level. Considering the positive sign of regression coefficient, it can be said that increase in impact (consequential influence) will improve occupational self-efficacy in the bank. Empowered individuals feel a personal control over the results. They believe that by affecting their work environment, they can change the outcomes. That is, in order for the outcome to be accompanied by the feeling of empowerment, they must feel that they are in control of their work results.

The results of the fifth hypothesis examination indicate that of the components of empowerment, only three (autonomy, impact, and meaningfulness) possess the capacity to predict self-efficacy of the employees in Greater Tehran branches of Mehr Eghtesad Bank. Since the component of competence lacks the criteria, it is excluded from the final regression equation.

\section{0- Suggestions}

\section{Suggestions regarding the dimension of meaningfulness:}

One way to increase meaningfulness is to emotionally stimulate the employees. Therefore, managers should try to establish a fresh and attractive workplace in the organization. They can also stimulate this feeling by holding regular social gatherings in order to enhance interpersonal relationships between employees and managers. To this end, they can train their employees on ways to reduce occupational tensions. Managers should also make the employees aware of a set of pre-determined and clear-cut objectives. Each employee should have a fair understanding of what he should do, as well as when and how to do it, while finding his job acceptable enough.

\section{Suggestions regarding the dimension of competence:}

The feeling of competence among employees is established by creating a sense of personal control. Personal control can be incentivized by providing opportunities to carry out harder tasks more successfully. To that end, tasks should be presented as challenges through job rotation. Hence, newly employed staff members should be gradually guided from simple and repetitive tasks toward more complex and specialized tasks. 


\section{Suggestions regarding the dimension of autonomy:}

Authorities in Greater Tehran branches of Mehr Eghtesad Bank are advised to offer their employees a certain level of independence (assignment of autonomy) so that they can determine the method and pace of their own jobs and turn into completely empowered individuals. Alongside the improvement of empowerment among them, the quality of services provided by Mehr Eghtesad Bank will be enhanced.

\section{Suggestions regarding the dimension of impact (influence):}

The recommended solution here is establishment of job identity. In this sense, the employees are given the opportunity to carry out a whole task. That is because if the employees only do a part of a job, they would not get to see the final outcome of their job and its impacts; this in turn would reduce their feeling of influence.

\section{Suggestions for future studies:}

- It is suggested that future researches study the relationship between empowerment and selfefficacy in other organizations and the results are compared and contrasted with those of the present research.

- Researchers are advised to conduct future researches on larger sample groups.

- It is suggested that future researches take a qualitative or combined approach to the study of the relationship between empowerment and occupational self-efficacy.

- Researchers are advised to study other factors contributing to occupational self-efficacy.

\section{References}

1. Damanpak H, 2012, identification of factors affecting employee empowerment and their impact on productivity in employees of Sepah Bank (East Tehran branches), Master's thesis, faculty of management, Islamic Azad University, Central Tehran branch

2. Tabarsa Gh, Ahangar N, 2008, employee empowerment, content, nature, methods, and applications, management perspective, 29:51-68

3. Forghani Toroghi O, Javanbakht M, Beyazi M, Sahebi A, Vahidi Sh, Derogar Kh, 2012, comparing the effectiveness of social-cognitive group learning and reality therapy on selfesteem of high-school students, principles of mental health, 14(2):172-180

4. Ghalaei B, Kadivar P, Sarrami Gh, Esfandiyari M, 2012, evaluation of teachers' selfefficacy models as a determinant of their job satisfaction and students' educational achievement, knowledge and research in educational sciences, 2(32): 95-107

5. Jazini A, 2006, factors affecting empowerment of NAJA staff officers, police knowledge periodical, 8(4): 9-25 
6. Davar V, Safaeian M, 2005, banking services marketing, Tehran, Negahe Danesh publication

7. Sadeghi A.M, Hassanzadeh A, Bagheri Gh, Amiri A.N, 2012, identification of intra- and extra-organizational factors affecting customer satisfaction in Salehin financial institute (Ayandeh Bank), $4^{\text {th }}$ international conference of banking services marketing, Tehran, October 2012, center for IRIB international conferences

8. Yousefzadeh M, Yaghoubi A, Rashidi M, 2012, the impact of meta-cognitive skill training on self-efficacy of female secondary school students, school psychology, 1(3): 118-134

9. Seyed Javadin R, 2009, human resources and employee affairs management, $3^{\text {rd }}$ edition, Tehran, Negahe Danesh publicatioin

10. Vacharakiat, M (2008). The Relationships of Empowerment, Job Satisfaction, and Organizational Commitment among Filipino and American Registered Nurses Working in the U.S.A. A dissertation submitted in partial fulfillment of the requirements for the degree of Doctor of Philosophy at George Mason University.

11. Savery.K.Law Son, J.Alanluks(2001) The Relationship Between Empowerment, Job Satisfaction and Reported Stress Levels Some Australian evidence.

12. Kanter, R. M. (1993). Men and women of the corporation (2 nd ed.). New York: Basic Books.

13. Butts, Marcus M., et al. (2009). Individual Reactions to High Involvement Work Processes: Investigating the Role of Empowerment and Perceived Organizational Support. Journal of Occupational Health Psychology. 14(2):122-136.

14. Conger, J. and Kanungo, R. (1988), "The empowerment process: integrating theory and practice”, Academy of Management Review, Vol. 13 No. 3, pp. 471-82.

15. Kinla D, 2004, human resource empowerment, translated by Iran Nejad Parizi M \& Salimian M, Tehran, Modiran publications

16. Narimani M, Vahidi Z, 2013, comparison of emotional defects, self-efficacy beliefs, and self-esteem in students with and without learning disability, learning disabilities periodical, 3(2): 78-91

17. Abdollahi B, 2006, the role of self-efficacy in employee empowerment, Tadbir monthly periodical, 17(168): 35-40

18. Amirsardari L, Rahimi M, Esmaeili A, 2014, the relationship between general self-efficacy and anxiety in police force employees, police medical periodical, 3(2): 95-100

19. Abdi F, 2013, the relationship between psychological empowerment, self-efficacy, and job satisfaction in employees of Western Carpet Company, international conference of management, challenges and solutions, Shiraz

20. Heidari A, 2013, the impact of psychological and organizational empowerment on human resource performance (case study: Besat hospital), M.A. thesis, faculty of social and economic sciences, Payame Nour University of Tehran province 
21. Fathi S, 2012, the effect of psychological empowerment on job performance and personal responsiveness of Urmia University in 2011-12 school years, M.A. thesis, faculty of literature and Humanities, Urmia University

22. Hosseini J, 2010, the relationship between empowerment and self-efficacy and job satisfaction in secondary school managers in Shiraz, M.A. thesis, faculty of educational sciences, Islamic Azad University of Marvdasht

23. Barzegar M, Mohammadi N, 2010, relationship between empowerment and job performance (case study: Marvdash County department of education employees), M.A, thesis, Marvdasht University

24. Luthans, F., Zhu, W., \& Avolio, B. J. (2006). The impact of efficacy on work attitudes across cultures. Journal of World Business, 41(2), 121-132.

25. Chan, W. (2007), Emotional intelligence and components of burnout among Chinese secondary school teachers in Hong Kong. Teaching and Teacher Education, 22(8):1042 -1054 .

26. Ernest, Chetse (2007) "The relationship between self-efficacy and intent to leave during organizational downsizing in an insurance organization” M.A dissertation, University of South Africa (South Africa).

27. Chang, B. G., \& Solomon, J. (2010). Stereotype threat test anxiety, and specific self efficacy as predictors of promo thin exam performance. Group \& Organization management. Vol. 35, pp. 77-107.

28. Spritzer,G.M. (1995). An empirical examination of a comprehensive model ofPsychological Empowerment in the workplace. American Journal of community psychology, vol.23 No.5.

29. Pourjafardoost K, 2007, the structure and normalization of self-efficacy test for 14 to 18 year old students in Karaj City high schools, M.A. thesis of psychology, faculty of Psychology and Educational Sciences, Allameh Tabtabai University 